\title{
Nations of Immigrants: Australia and the USA Compared
}

\section{edited by J. Higley, J. Nieuwenhuysen, and S. Neerup Northampton, MA: Edward Elgar Publishing, 2009 ISBN: $978-1848446366$ Hardcover US\$100; 206 pp.}

\author{
Reviewed by James Frideres \\ Department of Sociology \\ University of Calgary \\ frideres@ucalgary.ca
}

How will nations maintain their population in the face of decreasing fertility rates? What will be their policies to address international mobility? Who will decide? Can people come to a consensus as to what will produce a cohesive society? This book looks at the key sociological and demographic questions of structure in addressing these questions. If there ever was a time for a new look at the issue of immigration, now is the time. This volume is an update of a previous piece of work by Freeman and Jupp titled Nations of Immigrants: Australia, the United States, and International Immigration that was published nearly twenty years ago. Reading the two volumes together is illuminating, in that it gives the reader some insights and confidence that the earlier version was a good predictor of what the authors of the present book present. Both nations allow for comparison in that they originated as British settler colonies, and both have long been liberal democracies_although there are some substantial differences in terms of their political institutions. Moreover, both countries have variants of "multiculturalism" and have federal political systems in which states have important powers that sometimes conflict with federal powers. Thus, the similarities of structure allow for some powerful comparisons with regard to the current immigration system in each of the two countries.

The book begins by offering readers a comprehensive and compact overview of the field. The subsequent range of works, presented by a number of experts in the field, is broad and thorough. The material for the book is the outgrowth of a conference held in Prato, Italy, and authors were able to exchange information, critique, and subsequently revise their contributions. I should note that if you are not able to read the entire book, you will be enlightened by just reading the editors' introduction. It is what all scholarly works should be; analytical, factual, predictive, descriptive, and informative. Practitioners, scholars, policymakers, and others will find this book to be useful in their work and illuminating in the content. The contributing authors reveal a range of disciplines, e.g., Business and Law, Sociology, 
Economics, Government, Geographical and Environmental Studies, and Political Science, and thus the book has a distinct interdisciplinary approach in addressing the core issues of immigration.

Over all, the book is divided into five general topics: compositions and contours of recent immigration flows, policy convergences and divergences between the two countries, immigration's effects on their labour markets, policies aimed at integrating new groups of immigrants, and changing shapes of ethnic relations and multiculturalism in the two countries. Pairs of parallel chapters (one Australian, one American) by leading scholars provide data, analysis, and conclusions for each of the topics. In each case, the authors analyze the two countries' recent immigration intakes and their effects on labour markets and government policies. They also look at the impact of immigration on social cohesion and citizenship. For example, both are the world's leading "net brain drainers" in that they import more skilled workers than they export; both have well established "colour bars" that tarnish immigrant-host relationships, and both are major immigrant-receiving nations. Authors also note that contemporary immigration is taking place in a context of increasing social inequality. Data suggest that inequality is increasing to levels unseen since the early 20 th century.

The authors reflect on the geostrategic contexts of the two countries, and they assess how their respective national histories and institutions have created their current immigration policies. While all chapters cover the same issues, there are idiosyncrasies in each country that authors are forced to discuss. To begin with, Australia has opted for a "point" system to assess potential immigrants, while the USA continues to use "family reunification" as the basis of its immigration policy. Other differences lie in the geographical position of Australia and the United States. For example, in the U.S.A, closeness to Mexico and the Caribbean raises the issue of Latino immigration. It is clearly discussed, and the impact of such immigration flows is an integral issue of immigration for the U.S.A. At the same time, Australia, and its closeness to Asia, present unique issues that are far from the minds of Americans. Then there is the issue of illegal immigration. Today the USA has over 12 million illegal immigrants living and working in the country; a condition not approximated in any other country in the world.

Immigration is at the centre of many conflicts the world over, and particularly in the two countries under scrutiny in this book. The material presented is rich with descriptive accounts of how immigration policy is created and implemented in the two countries. By contrast, our ability to explain existing immigration policy and justify its support is far less developed. Juxtaposing two very different immigration policies allows the reader to evaluate the good, the bad, and the ugly of each, and then allows the reader to evaluate the outcome of such policies. Is one better than the other? Does it really matter what policy is in place? What elements of one policy might be incorporated into the other? How might immigration policy be repositioned to extract the optimal positive impact on society? These are issues that the reader will have to extract from the data presented-but for once, the data is there to be evaluated.

In general, the authors of the various chapters have made excellent use of the statistics, government reports, and policy information drawn from the USA and Australia. Scholars studying immigration elsewhere in the world can benefit a great 
deal from looking at the parallels and differences between the two countries. Most of the concepts and findings apply to many different societies, although there are some important differences that can help scholars refine our theories about immigration.

While the authors point out problems in both countries' systems of immigration, they are less sanguine in their assessment of the American immigration policies than those of Australia. Given the level of globalization, the authors recognize that any nation is now subject to economic and social events that take place beyond their borders. Regardless, Australia has developed a controlled, predictable, and transparent immigration policy. As such, it is supported by the general population. Its policies would seem to provide the necessary skills, drawn from a number of different countries, that will provide essential knowledge and a labour force for a growing economy, without fracturing its social cohesion. Quite the contrary for the USA, its immigration system is overwhelmed, outdated, and, some would say, no longer serves the nation's needs. Few Americans understand or support the current policy, yet they are loath to make changes. Partisan politics has hamstrung any attempts to revamp, modernize, and produce a functional immigration system. The question is: to what extent have the two nations structured themselves around class and racial fault lines that shape the experiences of immigrants and their offspring? Having read this book, you will have a good sense of how the two countries got to where they are today.

This clearly argued and perceptive study of immigration provides readers with an introduction to and analysis of the core issues in the immigration debate. Digging into massive archival sources and accumulating information from many government reports and policy, the authors provide a clear profile of the issues they have chosen to elucidate. By untangling the politics and the economics of various issues, the authors provide the reader with a clear view of immigration policies, legislation, and outcomes for the two countries. The book will be a good addition to policymakers', faculty, and student libraries, and they will find themselves going back to the book time after time for data and information that they can compare with their own country's history and statistics. Even though the focus is on two specific countries, it is a timely piece of scholarship and one that should be read by all those in the field of immigration. The editors are to be congratulated for putting together an excellent and timely book on immigration issues. 